\title{
Dramaturgias Del Personaje Contemporaneo: Fragmentación, montaje y collage
}

\author{
Maria Aparecida de Souza \\ Universidad Autonoma de Barcelona - UAB, Barcelona, Espanha \\ E-mail: mariasouzafloripa@hotmail.com
}

\section{Resumen}

El artículo propone una reflexión sobre los principios compositivos de las dramaturgias contemporáneas, con foco en el personaje y los procedimientos estéticos de fragmentación, montaje y collage. Dichas reflexiones abordarán la noción de Dramaturgias enfocando al texto dramático, como potencialidades reconocibles en la obra del dramaturgo.

Palabras-claves

Dramaturgias Contemporáneas. Personaje. Fragmentación.
Abstract

The article proposes a reflection about the composition principles belonging to contemporary dramaturgies, focusing into the character and the aesthetic procedures of fragmentation, staging and collage. These reflections will tackle the dramaturgies from the point of view of writing, as recognizable potentialities in the author work.

Keywords

Contemporary Dramaturgies. Character. Fragmentation. 


\section{Introducción}

El artículo propone una reflexión sobre los principios compositivos de las dramaturgias contemporáneas centrándose más específicamente en el personaje. Dichas reflexiones abordarán la noción de Dramaturgias enfocando al texto dramático como potencialidad reconocible en la obra del dramaturgo'.

Entre las metamorfosis por las cuales el teatro ha ido pasando en la contemporaneidad, destaca el cuestionamiento de los principios constitutivos de la dramaturgia asociados a aspectos de renovación del papel del dramaturgo delante del hecho teatral. La creación de estrategias exploratorias radicales, abren paso a una escritura diversa tanto en el plano temático como en el de las estructuras formales, alterando substancialmente los elementos que hasta entonces aún eran considerados como fundamentales de la dramaturgia y de la puesta en escena, como el personaje, la fábula, el diálogo y la acción dramática.

En el ámbito del drama tradicional ${ }^{2}$, el personaje como representación del individuo posee características físicas, estatus social, es portador de una historia, de un comportamiento psicológico y una identidad, próximos al universo referencial del lector/ espectador. También tiene a su cargo múltiples funciones: sostiene la fábula, conduce la acción, intenta alcanzar ciertos objetivos superando una cadena de obstáculos.

En las dramaturgias contemporáneas, el personaje, en tanto que persona, que representa un individuo, se presenta como una

$1 \mathrm{El}$ trabajo fue el resultado de mi investigación doctoral, Ihamada: Dramaturgia de la polifonía: Un estudio sobre las prácticas de enseñanza y aprendizaje de las escrituras dramaticas en el obrador internacional de la sala beckett de Barcelona realizada en la Universidad Autónoma de Barcelona.

2 Nos referimos al Drama Puro descrito por Peter Szondi (2011). El drama nasce en el Renacimiento, está subordinado al texto, tiene como foco una representación mimética y realista donde los personajes construyen relaciones intersubjetivas, y refleja a la tradición aristotélica. figura incierta cuyos objetivos son difíciles de descifrar; los trazos dominantes que definen sus contornos y fijan su identidad se encuentran cada vez más movedizos e incompletos.

En las dramaturgias más recientes que han captado nuestra atención, el principio ordenador, donde los personajes alternan el discurso en proporciones simétricas con el intercambio de réplicas lineales y fluidas, se reemplaza por una proliferación de dramaturgias híbridas e imprevisibles. Se vuelve difícil reconocer en los sujetos de la enunciación, características comportamentales que permitan identificar quién está pronunciando una réplica, al no haber ninguna acotación que describa características físicas o un conjunto de trazos o acciones atribuibles a un único personaje.

El montaje y el collage de fragmentos de diferentes géneros y extraídos de diferentes ámbitos: artísticos, científicos, religiosos, tecnológicos, generan una dramaturgia abierta, hibrida y múltiple. En lo que respecta a la perspectiva del colectivo escénico, (actores, directores, escenógrafos, etc.) las dramaturgias contemporáneas se presentan a sus prácticas como un campo de investigación nuevo, aún no asimilado del todo, por siglos de interpretación teatral, o como objeto de estudio delimitado, del cual pueda partir una trayectoria de investigaciones unificadas en torno a las mismas.

\section{Bases teóricas y metodológicas}

Frente a esta problemática, este articulo presenta, desde la perspectiva de la dramaturgia, los nuevos instrumentos de abordaje del personaje a partir de enfoques teóricos y prácticos. También propone identificar los principios compositivos de las escrituras contemporáneas, desde fragmentos de algunas piezas teatrales y al mismo tiempo, el modo en que estas piezas, desde sus distintas propuestas estéticas, pueden generar e impulsar 
no solamente prácticas novedosas y singulares, sino sobre todo, un proceso colaborativo entre la escritura y la escena, ampliando el concepto de dramaturgia para Dramaturgias.

Al emprender la tarea de abordar los procesos de interpretación teórica, conceptual y práctica de las dramaturgias de las últimas décadas, nos encontramos con un abanico de conceptos que intentan arrojar luz sobre algunas tendencias emergentes del teatro contemporáneo.

Dentro de los conceptos y terminologías utilizadas por teóricos del teatro y de la dramaturgia, podemos destacar: la crisis del personaje (Robert Abirached), teatro postdramático (Hans-Thies Lehmann), impersonaje (Jean-Pierre Sarrazac), composición-decomposición (Jean-Pierre Ryngaert y Julie Sermón) y fragmentación (Maria Lúcia L. Candeias). Buscaremos la intersección de las perspectivas teóricas de estos autores con las obras dramáticas que citaremos como ejemplo, con foco en el personaje y los procedimientos estéticos de fragmentación, montaje y collage ${ }^{3}$.

Dentro de la perspectiva de la dramaturgia contemporánea se pueden trazar ciertas correspondencias con el montaje y el collage como técnicas, expresiones artísticas y un compromiso ideológico en el que se complementan.

El concepto de collage hace referencia a las artes plásticas, y evoca las vanguardias históricas como el cubismo y sus primeros exponentes, Georges Braque: Bodegón con frutero y vaso (1912) y Pablo Picasso: Naturaleza muerta con silla de rejilla (1912).

En un primer sentido, el collage, según la definición del Diccionario Akal de Arte del siglo XX (2007, p.138) "Consiste en la irrupción de elementos en bruto directamente recogidos de la realidad e incorporados tal cual

3 Autor (Mayo de 2011), Collage: Técnica, Estética e Ideología. Horizontes do Brasil: Escenarios, Intercambios y Diversidad. XVI Seminario Internacional de la Asociación de Investigadores y Estudiantes Brasileños en Catalunya, 1804-1811. a la superficie del cuadro o la hoja de papel, construyendo una de las fisuras fundamentales que determinan el arte contemporáneo".

El montaje en el cine es "[...] la unión de los distintos trozos de película para crear una cinta final. Consiste en escoger, ordenar y unir una selección de los planos a registrar, según una idea y una dinámica determinada" (KONIGSBERG, 2004, p. 327). Sugiere la idea de una discontinuidad temporal, la interrupción del flujo natural de la obra para crear tensión y contraste entre las distintas partes separadas.

Aunque el collage esté más relacionado con el espacio y montaje con el tiempo (repetición y la variación de las partes), ambos son homologables a diferentes instancias del arte, y no se limitan al dominio del cine y de las artes plásticas, sino que abarcan entre otras, la música, la danza, la literatura, las artes escénicas en general y a la dramaturgia en particular.

En sus reflexiones sobre los procesos colaborativos entre el dramaturgista y el colectivo escénico, la dramaturgista Fátima Saadi propone que: "Idealmente, é a partir de afinidades que se establecem as parcerias entre coletivos de criação e dramaturgistas. No entanto, elas só funcionam se houver interesse manifesto pela discussão da produção de sentido "4.

Pensando en lo anteriormente expresado por Saadi, entendemos que la fragmentación del personaje efectuada mediante los procedimientos de montaje y el collage permite buscar su materia prima en diferentes lenguajes artísticos y en diferentes planos de la realidad; en este sentido alimenta el proceso dramatúrgico con otras dinámicas de composición y abre vías para que el colectivo escénico produzcan nuevas zonas de sentido y de representación.

4 SAADI, Fátima. Dramaturgias: estudo sobre a função do dramaturgista: Questão de Crítica - Revista eletrônica de criticas e estudos teatrais, 2013. Disponible: http://www.questaodecritica.com.br/2013/12/dramaturgias. Acceso en: 12/2/2019. 
En este sentido, la noción de Dramaturgias que proponemos aquí no se expande a los demás campos de acción del dramaturgo como por ejemplo: " [...] colaborar no delineamento do projeto artístico do grupo e na sua difusão; participar da escolha do repertório; ler e comentar peças que sejam enviadas para apreciação; traduzir, criar ou adaptar textos ou materiais que sirvam de base para o espetáculo [...]"5, mas bien, involucra especificamente el texto dramático previamente escrito por el dramaturgo. Utilizaremos como referencia la base que nos proveen los siguientes textos dramáticos, traducidos al español: Attempts on Her Life (2005), de Martin Crimp, Ansia (2001), de Sarah Kane, La soledad de los campos de algodón (2001), de Bernard-Marie Koltès.

Son obras que han generado un profundo proceso de renovación tanto en lo concerniente al nivel dramatúrgico como a nivel de la creación formal y temática del lenguaje teatral. Son dramaturgias ya inauguradas en experiencias teatrales cuyas posibilidades de puesta en escena y creaciones de los personajes son verdaderos desafíos.

Entendemos que estos desafíos inscritos en la misma escritura proponen un juego de cooperación entre el dramaturgo y los demás creadores de la escena, superando nociones como fidelidad al texto para dejar abierta la posibilidad de investigar nuevas elaboraciones formales y estéticas de la representación de la realidad y también, para proponer un cuestionamiento de la práctica teatral en todos sus niveles.

Cabe recordar que las obras aquí utilizadas como referencia no abarcan todas las formas dramatúrgicas de las últimas décadas, o toda la escritura dramática que se está

5 SAADI, Fátima. Dramaturgias: estudo sobre a função do dramaturgista: Questão de Crítica - Revista eletrônica de criticas e estudos teatrais, 2013. Disponible en:

http://www.questaodecritica.com.br/2013/12/dramaturgias. Acceso en: 12/2/2019. gestando en los modos contemporáneos de creación teatral. Otras muchas obras de no menor relieve comparten las mismas tendencias pero no pudimos incluirlas en nuestro análisis, por rebasar sus propios límites.

El personaje

En La crisis del personaje en el teatro moderno (1994), Robert Abirached, plantea que la misma está directamente vinculada a los grandes cambios respecto de la noción de mimesis, intrínseca ésta a su vez, a la noción de personaje aristotélico. Abirached sostiene que el objetivo de la representación mimética ha permanecido en el teatro europeo hasta el siglo XVIII, "como el de imitar las acciones de los hombres, por medio del juego del actor, a través de un espacio y un tiempo figurados, frente a un público invitado a creer en las imágenes construidas de esta manera" (ídem, p.89). En el itinerario sobre la figuración y la desfiguración que ha marcado al personaje, el autor también evidencia que la crisis del personaje moderno es a la vez la causa y consecuencia de la crisis del drama ${ }^{6}$. Para este autor, después de las obras de Samuel Beckett, el personaje en crisis sigue siendo el objeto de innumerables experimentaciones dramatúrgicas que desdibujan sus últimos trazos definidores para otorgarle otros estatutos.

6 La noción de crisis del drama fue propuesta por el teórico Peter Szondi en su obra Teoría del drama moderno (1880-1950): Tentativa Sobre Lo Trágico. Madrid, España: Dikison, 2011. El autor analiza las consecuencias que la misma representa para el género literario "dramático". Para sostener su teoría, evoca los orígenes históricos de dicha crisis desde sus primeros síntomas, situados en torno a 1880 . 
En sus reflexiones Abirached (1994) describe que la reinterpretación de la mimesis aristotélica emprendida en el siglo XVIII por Diderot $^{7}$ y la demanda realista de la sociedad burguesa y del teatro naturalista, el personaje, "carácter", "máscara", que antes representaba a los nobles y a los mitos, como los héroes de las tragedias griegas, va adquiriendo rasgos humanos, transformándose en reflejo de los hombres y en individuos, con un estado civil, una personalidad, un perfil psicológico y una identidad más precisa, contribuyendo al ilusionismo de la persona humana y a la identificación del espectador con la misma.

Este personaje psicológico portador de una individualidad, determinado por un carácter, al que puede denominarse "íntegro", (CANDEIAS, 2012), es un personaje cuya construcción psicológica conserva un trazo dominante, y que movido por una voluntad determinada aspira a cumplir ciertos objetivos.

Pero, si hay un tipo de personaje que es íntegro, ¿Que sería un personaje "des-integrado"? Podemos decir que el personaje des-integrado es sinónimo de personaje fragmentado. En su estudio A fragmentação da personagem (2012), Candeias define el personaje fragmentado por "la ausencia de un traço dominante que o torne definido" (Ídem, p. XVIII), y observa fenómenos de fragmentación y yuxtaposición en los héroes de la tragedias griegas. Al mismo tiempo como una tendencia que se amplió en el siglo XIX y que persiste hasta la actualidad. Destacamos a continuación algunos de los rasgos que la autora plantea para caracterizar a un personaje fragmentado:

7 Entre las obras de los teóricos ilustrados, la de Denis Diderot, publicada en 1758, Discours sur la poésie dramatique (2009), sentó las primeras bases de una renovación del drama, permitiendo un alejamiento de las reglas del teatro clásico. El dramaturgo y filósofo francés propuso una forma dramática que marcó un nuevo estado de realización del drama, más próxima a lo cotidiano de los individuos, y a los intereses y valores de la nueva clase social en ascenso, la burguesía, favoreciendo la identificación con el público.
Trata-se, a grosso modo, da apresentação de personagem que não têm caráter linear, personalidade fixa, mas traços em justaposição [...] sua estrutura psicológica é mais esmiuçada, mais complexa que aquelas apresentadas por personagens do drama romântico (idem, p. XVIII)

Es decir, la fragmentación del personaje no es un procedimiento nuevo, cobra múltiples sentidos y se puede rastrear en diferentes obras teatrales de diferentes momentos de la historia del teatro. Pero, si tomamos como punto de partida la crisis del drama a partir de fines del siglo XIX hasta nuestros días, podríamos hablar de una "cultura de la fragmentación del personaje", que es análoga a un momento histórico y filosófico que empieza a cuestionar nociones como las de identidad y de individuo. Sabemos que el sentido, la forma y la percepción que adopta el personaje en cada momento histórico corresponde a los valores culturales, principios estéticos, e ideológicos y a la correspondiente visión que el dramaturgo tiene del hombre en este contexto.

La Fragmentación del personaje gestada en el teatro moderno, vigente en el teatro contemporáneo, puede entenderse como una metáfora de la crisis del sujeto y de la identidad. Haciéndose eco de los cuestionamientos identitarios de la sociedad, la dramaturgia contemporánea problematiza la categoría del "yo" y las formas que permiten la transposición teatral de un ser humano identificable, íntegro y sin fisuras.

A propósito de los cambios que se han producido respecto al concepto de identidad en la contemporaneidad, podemos citar el sociólogo Zygmunt Bauman cuando habla de la fragilidad, y de la vulnerabilidad de la noción de identidad:

"Como consecuencia de una socialización excesiva en los hábitos consumistas, que reducen la capacidad de la atención humana y el tiempo de reflexi- 
ón y de planificación, valores como el de la identidad han sido relativizados y sustituidos por otros más provisionales y efímeros" (Bauman, 2005:144).

No obstante, lejos de entender este fenómeno de manera apocalíptica, Bauman aduce que esta misma inestabilidad es lo que da la oportunidad y la libertad necesarias para crear nuevas configuraciones identitarias que pueden responder a las distintas mutaciones, a las que el sujeto ha de enfrentarse a lo largo de su vida: "Se ha dado plena libertad a las identidades y ahora son hombres y mujeres concretos quienes tienen que cazarlas al vuelo, usando su propios medios e inteligencia" (idém, p. 68).

También en el ámbito de la dramaturgia, la creación de los personajes, produce nuevos efectos y nuevas configuraciones. De hecho, el personaje se despoja poco a poco de sus configuraciones totalizantes para convertirse en un ser moldeable, que gana existencia a través de otros modos de construcción y de expresión.

\section{La figura}

La noción de figura se aproxima a las artes plásticas y remite a la noción de trazos, de superficie, de forma. En el ámbito teatral la Figura (Ryngaert; Sermon, 2006) reemplaza al personaje considerado como persona, como entidad substancial, con un conflicto intersubjetivo, y con identidad psicológica por un juego de trazos hechos de montaje y collage. Entre las diferentes tendencias a través de las cuales se manifiestan las figuras en los procesos de fragmentación y renovación del personaje contemporáneo, puede señalarse en primer lugar la falta de nombre, es decir, la "separación" del personaje de su nombre propio. En el teatro, la elección del nombre del personaje, tiene importancia sobre la representación imaginaria ficcional y afectiva del espectador. En un número considerable de obras contemporáneas, como algunas de las que forman parte de este estudio, los personajes son anónimos, caracterizados por letras $(A, B, C)$ género (mujer/hombre), por su función (cliente, vendedor), por la edad (el joven, la anciana), etc. Transformado en un ente privado de su nombre, el personaje pierde uno de sus atributos más significativos. Va dejando lagunas en su integridad, dificultando la atribución de un determinado carácter y cualquier tentativa de análisis psicológico.

La pieza La soledad en los campos de algodón, del dramaturgo Bernard-Marie Koltès, ilustra las posibilidades de este personaje-figura. El inicio de la obra presenta solamente la definición del tráfico:

\begin{abstract}
Un deal es una transacción comercial referente a valores prohibidos o estrictamente controlados, que se realiza en espacios neutros, indefinidos, y no previstos para tal uso entre proveedores y clientes por acuerdo tácito, signos convencionales o conversaciones con doble sentido, con el propósito de evitar los riesgos de traición y estafa que implica una operación de esa naturaleza, a cualquier hora del día y la noche, independientemente de las horas de apertura reglamentarias de los comercios aceptados y, por lo general, a la hora de cierre de los mismos (KOLTĖS, 2001, p.2).
\end{abstract}

Dealer y cliente realizan lo que sería una transacción comercial permutando "casi-monólogos" - término acuñado por Ubersfeld (2004) - para referirse a una variación del monólogo clásico, marcado por la ausencia de respuesta o de cambio dialogal.

Estas figuras no enseñan trazos que caractericen a la identidad o a la biografía, no expresan sus mundos interiores. Sus definiciones posibles se realizan más por las palabras que pronuncian que por las acciones que realizan. Sarrazac (2006), observa que el discurso de estas figuras remite a un 
debate de ideas donde cada uno utiliza la argumentación de forma sofisticada para persuadir al otro. En la superficie del texto, estas figuras son yuxtapuestas, dentro del sujeto híbrido, sujeto épico, sujeto-líri$\mathrm{co}$, que pueden dejar tras parecerse como vendedor/comprador, como hombre/animal, masculino/femenino, blanco/negro, etc.:

Dealer: veo su deseo como quien ve la
luz que se enciende, en la ventana de un
edificio, al anochecer; me acerco a usted,
como el anochecer se acerca a esa pri-
mera luz, suavemente, respetuosamen-
te, casi afectuosamente, dejando muy
abajo en la calle al animal y al hombre
tirar sus correas y mostrar salvajemente
los dientes. No es que haya adivinado lo
que usted desea, ni que esté apurado
por conocerlo; porque el deseo del com-
prador [...] algo que se contempla como
un secreto que solo pide ser descubierto
y con el cual nos tomamos un tiempo
antes de hacerlo [...] (KOLTĖS, 2006,
p. 2). Cliente: No conozco ningún cre-
púsculo ni ningún tipo de deseo y quiero
ignorar los accidentes de mi recorrido.
lba desde esa ventana iluminada, detrás
de mí, allá arriba, hasta esa otra ven-
tana iluminada, allá, en frente de mí, a
través de una línea muy recta que pasa
a través suyo, porque usted se situó
deliberadamente ahí (Ídem, 2006, p. 4 ).

En el caso de la pieza anteriormente citada, la fragmentación espacio-temporal, el uso de puntuaciones, de figuras retóricas como la aliteración, el paralelismo sintáctico, etc., son la manifestación de una forma expresiva que intenta provocar la des-realización de los referentes lingüísticos y sonoros.

Todo este lenguaje compositivo, aparece entretejido por un hilo intencionadamente paródico. Las figuras que tratan de una transacción comercial, ironizan el arte de la retórica. Introducen otro discurso y otra orientación al "buen arte de hablar" (RYNGAERT, 2013).

En este "repertorio de las mil y una maneras de decir" (UBERSFELD, 2004, p.22), las palabras están más centradas en la fuerza poética que en la acción; por ello, Heiner Müller llama a los casi-monólogos de Koltès estructura de arias, acepción que remite a una canción formalmente lírica y autónoma para una sola voz, que por lo general forma parte de una ópera (LATHAM, 2008). Lo que nos conduce a pensar en una dramaturgia, que entra en diálogo directo con otros lenguajes artísticos y con la voz del actor, y propone una nueva escucha de aquellos que deseen llevarla a la escena.

Por su composición fragmentada, en la que las escenas promueven una indeterminación de los referentes espacio-temporales, la obra ofrece un principio de expansión y de potencialidades lo que puede generar una profunda libertad y apertura creativa para que el colectivo escénico pueda aportar nuevas estructuras.

La figura plantea al colectivo escénico, la posibilidad de transformar el personaje en agente de un lenguaje performativo, poético y rítmico, que sobrepasalos modos de significación reconocibles y evidentes para provocar otras formas de significación del personaje.

\section{El impersonaje}

El término "impersonaje", propuesto por Sarrazac, posee a grosso modo las mismas características que el término "figura", con la diferencia de que Sarrazac lo construye en torno al concepto de carácter. El impersonaje es un ser sin carácter. Es decir, no hay en él intrínsecamente virtud o vicio. No se le puede atribuir cualidades, o trazos morales.

El carácter se describe en la poética de Aristóteles (1450 a 5-12) como "aquello según el cual, decimos que los que actúan son tales o cuales [...] aquello que manifiesta decisión". Abirached, interpretando a Aristóteles, afirma que "carácter es la línea de conducta general de un personaje", "los hombres son de esta o de otra manera según su carácter" (1994, p.33). Carácter (ethos) es un conjunto de trazos morales (vicio y virtud) y la línea de conducta del personaje, construida a partir de sus acciones.

Sarrazac (2006) constata, desde un cierto punto de vista, que la pérdida del carácter del personaje - que empieza a manifestarse a partir del drama moderno -, se ha transformado paulatinamente en una opción estética recurrente y en uno de los signos capitales del teatro contemporáneo.

El personaje es el lugar de la "confrontación y de la diferencia de sus suce- 
sivas máscaras" (SARRAZAC, 2006, p. 356). La falta de carácter y personalidad del impersonaje, no se considera como un déficit o una despersonalización negativa porque, paradójicamente, el impersonaje está provisto de múltiples persona-máscaras, sin unidad ni marco conclusivo.

Como ejemplo de este estatuto del personaje, podemos citar la obra Attempts on Her Life (2005), de Martin Crimp, que en la introducción de esta obra afirma: "Esta es una pieza para un colectivo de actores cuya composición debería reflejar la composición del mundo más allá del teatro"8.

La obra presenta los personajes como: hombre I; hombre II hombre III; hombre IV; está fragmentada en diecisiete relatos o escenas, construidos de manera independiente, al que el autor describe del siguiente modo:

17 escenarios para el teatro: 1 . todos
los mensajes han sido borrados, 2 .tra-
gedia de amor e ideología, 3. Fe en
nosotros mismos. 4 . El ocupante o in-
quilino. 5. La cámara te ama. 6 . Mamá
y papá, 7. El nuevo Anny, 8. Partículas
Físicas, 9. La amenaza del terroris-
mo mundial, 10. "medio divertido", 11.
Sin título (100 palabras), 12. Extraño,
13.comunicandose con extraterres-
tres, 14. La chica de al lado, 15. La
declaración, 16. Porno, 17. Previamen-
te congelado9 (CRIMP, 2005, p. 199).

Estos cuadros no presentan espacios y tiempos determinados, y orbitan alrededor de un mismo personaje, siempre ausente: Anne. Diferente de los demás personajes, que no reciben nombres propios, Anne, personaje matriz, tiene su nombre multiplicado

8 "This is a piece for a company of actors whose composition should reflect the composition of the world beyond the theatre". (La traducción es nuestra).

9 All Messages Deleted, Tragedy of Love and Ideology, Faith in Ourselves, The Occupier, The Camera Loves You, Mum and Dad, The New Anny, Particle Physics, The Threat of International Terrorism $^{\mathrm{TM}}$, Kinda Funny, Untitled (100 Words), Strangely, Communicating with Aliens, The Girl Next Door, The Statement, Porn and Previously Frozen (CRIMP: 2005, p.199). (La traducción es nuestra). en distintas versiones: Annie, Anya, Anna o Anny, según el país, o la situación donde ella se encuentre. Sólo intuimos a Anne a través del relato de los narradores, seres que, como Anne, no poseen identidades definidas.

A lo largo de la pieza, Anne va dejando huellas de las situaciones que supuestamente ha vivido, estableciendo y al mismo tiempo rompiendo los puntos de contacto entre los diferentes escenarios de su vida. En la medida en que avanza la pieza, podemos ver temas o palabras sonando como ecos en los cuadros que van subsiguiéndose. Por ejemplo, en la primera escena suena una voz en un contestador dando instrucciones a Anne sobre la organización de un posible atentado. Esta escena se conecta con la escena nueve, que sugiere el juicio de Anne por haber cometido un atentado terrorista. En el cuadro dieciséis ("Porno") encontramos una tercera voz, la de una locutora que tiene su discurso traducido simultáneamente en diferentes idiomas: africano, latino americano, europeo. - She's young and fit, and happy with her body.- (translation) / How she uses her body is her decision. (translation) / - Obviously. - (translation) I - Porn doesn't stop her leading a normal life. - (translation) (ídem, p.270-271) ${ }^{10}$. Los discursos de los narradores que juegan con fragmentos del pasado, y las aspiraciones de Anne, están atravesados por el montaje y el collage de pedazos de materiales de diferentes ámbitos: poemas, discursos publicitarios y ecológicos, listas, grabaciones, canciones, interrogatorios. Las mil y una posibilidades de Anne (artista, terrorista, víctima, amante, prostituta, suicida), no son asignables a una forma fija y no convergen en dirección a definiciones concluyentes sobre el personaje o sobre un punto de vista fijo. La

10 [...] Ella es joven, y está en forma, y feliz con su cuerpo (traducción)/. Como ella use su cuerpo es decisión de ella (traducción)/. Obviamente (traducción)/. El porno no le impide llevar una vida normal 
ausencia de Anne se puede contrastar con el potencial de versiones sobre la misma, es decir, Attempts on Her Life invita al colectivo que desee llevarla a la escena a experimentar en todo momento la relatividad de todo lo que caracteriza a la identidad de Anne y al mismo tiempo realizar la confrontación y la diferencia de sus sucesivas máscaras.

\section{El personaje postdramático}

Para formular sus planteamientos estéticos sobre el teatro postdramático,

Lehmann (2007), contrapone este último a las nociones de teatro-dramático. Para Lehmann, el teatro postdramático, incorpora una multiplicidad de nuevos lenguajes artísticos, como la performance, la danza, la música y el circo, y otros lenguajes audiovisuales como el video, tal como lo podemos ver reflejado en el teatro de Heiner Müller, Tadeus Kantor, Bob Wilson o Howard Barker.

Dentro de esta perspectiva, el teatro postdramático debe entenderse como una práctica de la autonomía y de la liberación del teatro respecto del drama y en relación al texto como elemento central, y al mismo tiempo, la dilución de conceptos como, personaje y representación.

Aunque el teatro postdramático integre en la escena elementos textuales, que incluyen piezas de teatro, el texto pierde su estatuto central para transformarse en una materia escénica como las demás una vez que el "conceito de texto dinamizou-se" [...] dando lugar "a 'escrita' com seu caráter fundamentalmente aberto, inacabado e polissêmico". (LEHMANN, 2007, p.26).

Los argumentos que sustentan al teatro postdramático también acentúan la dimensión performativa de la escena y de la palabra; la escena, más que un lugar de representación, se transforma en un lugar de juego, de acontecimiento, en un "aquí y ahora". Esta es la razón de la aproximación del teatro postdramático a formas artísticas consideradas como efímeras, provisionales, donde no se trata solamente de imitar, mostrar o reproducir el mundo, sino de compartir el momento.

Las formulaciones teóricas de Lehmann sobre el teatro postdramático han sido interpretadas por críticos, artistas y teóricos como una tentativa de señalar la muerte del drama y la incompatibilidad del texto dramático con la escena contemporánea. Lehmann, sin embargo, refuta estas interpretaciones afirmando que no es la inexistencia del texto dramático lo que garantiza un teatro postdramático, sino el uso que se hace de estos textos en la escena: "sencillamente cambia su estatus y, al hacerlo, crea nuevas posibilidades en vez de eliminar las antiguas"11.

En el Teatro Postdramático (2007), la dimensión textual comparte escena con las dimensiones visual y sensorial, optando por imágenes sugestivas, donde la organización no tiene lógica aparente. Los relatos o discursos de personajes o narradores se presentan sobretodo como una la superposición de palabras, frases, poemas, que oscilan entre "narrações delongadas e episódios de diálogo espalhados aqui e ali" (LEHMANN, 2007, p.185), lo que evidencia que el post dramático incluye poéticas de la fragmentación, al tiempo que dinamitan el personaje haciéndolo agente de una dramaturgia que busca la performatividad de la palabra y un proceso de co-escritura entre el dramaturgo y el colectivo escénico en general.

Lehmann parece encontrar en las obras de Sara Kane elementos que justifican su inclusión en el panorama postdramático. La autora explora procedimientos como el montaje y el collage y también de las dimensiones rítmicas y poéticas de la palabra, una vez que

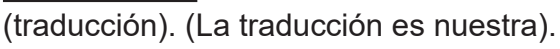

11 Entrevista concedida a Revista Pausa, "Llengua i Teatre" $\mathrm{n}^{\circ}$ 29, 2008, pp. 43-51. 
se aproxima a la poesía y de la musicalidad.

Entre las creaciones de la autora podemos citar la pieza Ansia (2006), donde cuatro voces $A, B, C, M$, con pocos trazos reconocibles, además de los de género, cruzan réplicas que van de monosílabos, hasta un largo monólogo central. A puede ser un anciano, $B$ un joven, $C$ una niña, $M$ una mujer (KANE, 2006, p.40-41).

Estos espacios rítmicos y sonoros invitan a una búsqueda de las posibilidades expresivas de la palabra del personaje mediante la voz y el cuerpo del actor. En las formas dialogales de los personajes es necesario la investigación de la sonoridad y la musicalidad de las palabras a enunciar. Estos se incorporan como elementos para obtener efectos semánticos sobre el tema o los temas de la obra.

El hecho de que los personajes tengan sus contornos cambiantes, durante los cambios de réplicas resulta evidente sus caracteres escindidos, sus ambigüedades y la fragmentación interna. Sus palabras están atravesadas por otras palabras. Esta idea puede presentarse metafóricamente cuando en algunos momentos de la pieza los personajes hacen suyas las palabras de los otros: B. pienso en voz/ A. Sueño con voz/ B. Hablo de voz (ídem, p.47). B. Me duele la espalda/C. Me duele la cabeza/A. Me duele el Alma. (ídem, p.36). Al mismo tiempo esta simbiosis se disuelve cuando el personaje habla un idioma diferente como en serbocroata: "B. Meni ni iz dzepa, ni u dzep" (ídem, p.38); o en alemán: "B. Du bist die Liebe meines Lebens" (idem). De la misma forma los personajes se encuentran definidos, por un juego de montaje y collage de réplicas que sugiere personalidades efímeras.

La palabra del personaje no es una palabra organizada de forma directa y unilateral, es una palabra abierta y de múltiple orientación. La palabra del personaje parece tener autonomía para seguir su flujo y combinarse de múltiples formas. Kane extrapola las fronteras del drama y busca en otros lenguajes expresivos material para construir otras formas de personajes. Asimismo, la autora privilegia estrategias de montaje y collage de otros géneros discursivos, y modalidades expresivas como citas del poema The Waste Land (La tierra Baldía), 1922, de Thomas Stearns Eliot: A. Crucé dos ríos y lloré junto a uno (Ídem, p.54); también frases de la Biblia: A. Pero el Señor me ha bendecido con la marca de Caín; Génesis 4:15 50. ( ídem p. 79) / B. Aquello que temo se cierne sobre mí (ídem, p. 41); frase repetida en la pieza por lo menos cinco veces (mayúsculas en el texto original): "M. APURATE YA ES LA HORA" (ídem, p. 30).

Esta forma particular de proponer los personajes tanto en lo que se refiere a su instancia rítmica musical, como a su estrategia de montaje y collage de textualidades heterogéneas propone un desafío estético para los actores y para los componentes de la puesta en escena en general.

Para reconstruir el universo de estas entidades postdramáticas es necesario salir de un espacio dialogado instituido, para arriesgarse a otra escucha, y a otra experiencia de (de) composición del personaje.

Reflexiones

A partir de estas consideraciones, puede observarse que es sumamente difícil describir las dramaturgias contemporáneas dentro de un espacio conceptual, formal y teórico consensuado.

La transformación histórica que ha experimentado el concepto de dramaturgia y de personaje remite a la multiplicidad de caminos y discursos teóricos que han contribuido a reflexionar sobre las nociones de individuo y de identidad. El tema de la identificación del personaje se presenta como un espacio 
de reflexión y de puesta en cuestión, sobre el lugar que ocupa la noción de persona, individualidad y unidad como formas representativas y constitutivas del sujeto contemporáneo.

En el transcurso de esta investigación, hemos observado que la fragmentación del personaje no es un aspecto aislado de la dramaturgia actual. Con todo, la frecuencia y las múltiples formas de fragmentación de sus elementos constitutivos no se presentan como una modalidad única, sino como una estructura formal que acoge un número plural de formas de realización.

Respondiendo a la hegemonía de la unicidad del personaje como representación del sujeto, la dramaturgia contemporánea fragmenta todo lo que puede formar la unicidad del mismo y da lugar a voces pluralizadas, a configuraciones caleidoscópicas.

Las obras contemporáneas que hemos abordado en este artículo se inclinan por una poética que, tanto desde el punto de vista de la forma como del contenido, presentan una estructura fragmentada, que se realiza o infiere a través del potencial del lenguaje, del montaje y del collage, de una heterogeneidad de estilos, y la yuxtaposición de textualidades teatrales y extra-teatrales.

Hemos visto que las nociones de "figura", "impersonaje", y "personaje postdramático", tres formas de designar al personaje contemporáneo, abogan por una comprensión de la noción de personaje que no implica en la asignación de atributos definitorios más bien, representan el despojamiento de su naturaleza totalizadora, para dar lugar a trazos con autonomía y significado, provocando el perspectivismo múltiple sobre el personaje. Es por esta razón que las potencialidades de su puesta en escena son flexibles e innumerables. Para estos autores, el personaje pierde algunos de sus atributos, aunque al mismo tiempo gana existencia, a través de otros modos de construcción y expresión.
Así mismo, si los autores contemporáneos han separado al personaje de sus marcos de significación reconocibles en contrapartida se han interesado por sus nuevas posibilidades, buscando a través de la misma práctica de la escritura su materia prima en diferentes lenguajes artísticos, en diferentes géneros y planos de la realidad; en este sentido alimentan y potencializan la escritura con otras dinámicas de composición y abren vías para que los demás integrantes de la escena penetren dentro de nuevas zonas de producción de sentido y de representación.

Desde estas reflexiones nos arriesgamos a decir que las propuestas dramatúrgicas de las obras aquí citadas absorben la acepción de "Dramaturgias" del personaje contemporáneo, una vez que sus autores provocan desde la misma escritura, otras configuraciones y alternativas que desvelan otros sentidos sobre este componente central del teatro, el personaje.

Referencias

ABIRACHED, Robert. La crisis del personaje en el teatro moderno. Madrid, España: Asociación de Directores de Escena de España, 1994.

BAILLET, F., BOUZITAT, C. Muntatge i collage, in SARRAZAC, Jean Pierre. Lèxic del drama modern. Barcelona, España: Institut del Teatre, 2009.

BAUMAN, Zygmunt. Identidad. Buenos Aires: Losada, 2005.

CANDEIAS, Maria Lúcia L. A Fragmentação da personagem no texto teatral. São Paulo, Brasil. Perspectiva, 2012. 
CRIMP, Martin. Plays 2: Attempts on her life. Contemporary Classics. London: Faber \& Faber, 2005 (a).

DE SOUZA, Maria A. (Mayo de 2011), Collage: Técnica, Estética e Ideología. Horizontes do Brasil: Escenarios, Intercambios y Diversidad. XVI Seminario Internacional de la Asociación de Investigadores y Estudiantes Brasileños en Catalunya, 1804-1811.

DIDEROT, Denis. De la poesía dramática. Madrid, España. ADE, 2009.

KANE, Sarah. Ansia, 4.48 Psicosis, (Trad. Rafael Spregelburd). Buenos Aires, Argentina: Losada, 2006.

KOLTÈS, Bernard-Marie. En la soledad de los campos de algodón, Trad. Nathalie Cañizares Bundorf. Hondarribia, Gipuzkoa, España: Hiru, 2001.

KONIGSBERG, Ira. Diccionario técnico akal de cine. Barcelona, España: Akal, 2004.

LEHMANN, Hans-Thies. In "Llengua i Teatre", Revista Pausa, n² 29, p. 43-51, 2008. Hans-Thies. Teatro Pós-Dramático. São Paulo, Brasil. Cosac Naify, 2007.

NOUJAIM, Marianne. Le Théâtre de Michel Vinaver - Du dialogisme à la polyphonie. $\mathrm{Pa}$ ris, Francia: L'Harmattan, 2012.

RYNGAERT, Jean-Pierr. SERMON, Julien. Le personage théâtral contemporain: décomposition, recomposition. Paris, France: Editións Théâtrales, 2006.

RYNGAERT, Jean-Pierre. Ler o teatro contemporâneo. São Paulo, Brasil: Martins Fontes, 2013.
SAADI, Fatima. Estudo sobre a função do dramaturgista. Questão de Crítica: revista eletrônica de criticas e estudos teatrais. Disponível em: http://www.questaodecritica. com.br/2013/12/dramaturgias/. Acesso em 12/2/2019.

SARRAZAC, Jean-Pierre. El impersonaje: una relectura de la crisis del personaje. Revista Literatura: teoría, historia, crítica, $\mathrm{n}^{\circ} 8$, p. 353-369, 2006.

Jean-Pierre. Lèxic del drama modern i contemporani. Barcelona, España: Institut del Teatre, 2009.

SZONDI, Peter. Teoria del drama moderno (1880-1950). Madrid, España: Dikison, 2011.

UBERSFELD, Anne. Bernard-Marie Koltès. France, Arles: Actes Sud, 2004.

WESCHERr, H. La historia del collage: del cubismo a la actualidad. Barcelona, España: Gustavo Gili S.A, 1976.

Recebido: $24 / 04 / 2019$ Aprovado: 17/10/2019 